\title{
Portal into history of medicine, humanities
}

Cite as: CMAJ 2017 March 6;189:E377. doi: 10.1503/cmaj.1095392

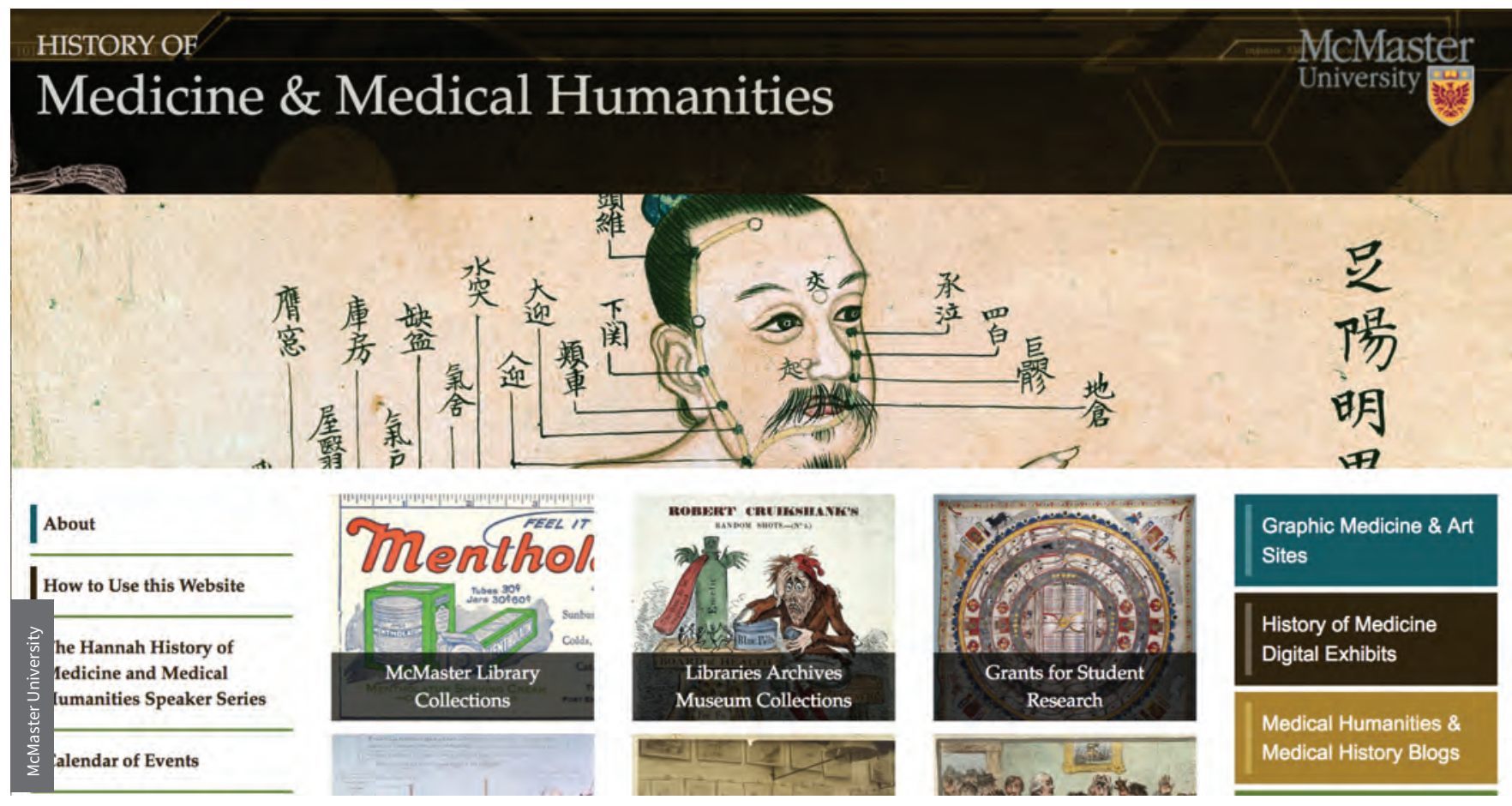

Access to libraries, archives, digital collections and more is available through the new portal.

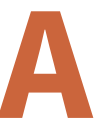
re you stymied in your search for a historic image? Wondering if there's a fellowship on the history of blindness? Need to unearth homeopathy's roots? There's now one-stop shopping for all this and more through McMaster University's new History of Medicine and Medical Humanities Research Portal.

The evolving portal already contains more than 400 pages of original descriptions of libraries, archives, museums, digital collections, blogs, grants and more. It also represents two years of intensive work by Professor Ellen Amster, McMaster's Jason A. Hannah Chair in the History of Medicine.

"There's a lot of information available online, but you have to hunt around for it," said Amster. "I wanted to create a portal that would bring those resources together in one place."

Amster's job is to support people interested in the history of medicine in every edu- cation program at all levels, as well as MD students. She quickly realized the latter don't have time to take a whole course. Her solution was to create this resource for everyone.

Students may use it to look up one detail, or it could be the starting point for a full-fledged research project.

"I created this so if student came to me and said I want to do a project on genetics, neurology, or whatever, I would have some kind of infrastructure for them to draw upon."

Amster will also use it for her classes. For example, the Eugenics Archives has an interactive time line, and interviews with survivors of sterilization and eugenic programs in Canada. "I use it to teach a history of public health class. The students love it," she says.

"Everything Darwin wrote is digitized and on a website. You can get hundreds of Florence Nightingale letters. And there's more coming on all the time," she explains. "We should be taking advantage as much as possible."

Amster did much of the work herself with help from the university's computer services. She also hired a designer, and an undergraduate and three doctorate students in history to help pull it all together. Funding of $\$ 40000$ came from the Associated Medical Services, as well as McMaster's DeGroote School of Medicine and the Faculty of Health Sciences.

The next steps are to add a search function and populate the six thematic boxes (located on the site below the top three boxes). Amster is also creating a medical humanities group at McMaster, including a humanities boot camp, to expand its current offering on the art of seeing.

"It's new and interesting and the students really want it," she says.

Barbara Sibbald, CMAJ 